\title{
Pheochromocytoma during pregnancy - a rare diagnose with a complex multidisciplinary approach
}

\author{
Rita Silva ${ }^{1 *}$, Catarina R. Carvalho' ${ }^{2}$ Madalena A. Tavares 3 , \\ Célia Pedroso $^{3}$, Paula Tapadinhas ${ }^{3}$
}

\author{
${ }^{1}$ Department of Obstetrics and Gynecology, Hospital Vila Franca Xira, Portugal \\ ${ }^{2}$ Department of Obstetrics and Gynaecology, Centro Hospitalar Lisboa Norte, Hospital Santa Maria, Portugal \\ ${ }^{3}$ Department of Obstetrics and Gynaecology, Hospital Vila Franca Xira, Portugal
}

Received: 21 July 2021

Accepted: 12 August 2021

\section{*Correspondence:}

Dr. Rita Silva,

E-mail: rita.sccsilva@gmail.com

Copyright: (C) the author(s), publisher and licensee Medip Academy. This is an open-access article distributed under the terms of the Creative Commons Attribution Non-Commercial License, which permits unrestricted non-commercial use, distribution, and reproduction in any medium, provided the original work is properly cited.

\begin{abstract}
Hypertension is a common problem in pregnancy that can result in significant maternal and fetal morbidity and mortality. The common causes include pre-eclampsia, gestational hypertension and essential hypertension. Although pheochromocytoma is a rare of hypertension in pregnancy, it can lead to potentially life-threatening cardiovascular complications for the mother and increased fetal mortality if left undiagnosed and untreated. Early diagnosis and timely, appropriate management reduce possible maternal and fetal complications. We report a case of a 32-week pregnant woman diagnosed with hypertension secondary to pheochromocytoma. An elective caesarian section was performed at 37 weeks of gestational age and underwent a laparoscopic left adrenalectomy with success. A multidisciplinary approach is of utmost importance and essential during the management of this life-threatening condition during pregnancy.
\end{abstract}

Keywords: Pheochromocytoma, Hypertension, Pregnancy

\section{INTRODUCTION}

Pheochromocytoma is a tumor arising from adrenomedullary chromaffin cells that commonly produces one or more catecholamines: epinephrine, norepinephrine, and dopamine and is a rare tumor causing secondary hypertension in about $0.1-0.2 \%$ cases. $^{1}$ Its incidence duraing pregnancies is less than 0.2 per 10.000 cases. ${ }^{1}$ This a potential life-threatening condition for both the mother and the fetus. ${ }^{2}$ Different approaches to medical treatment, timing and route of delivery, preoperative management, and timing of adrenalectomy have been tried, but neither consensus has been found nor guidelines have been published leading to optimal management. ${ }^{3}$ In the current report, we discuss a case of pheochromocytoma that was diagnosed during pregnancy, at thirty-two weeks of gestation, and the complexity of its management. This case illustrates that the timely antenatal diagnosis of pheochromocytoma, along with a proper preoperative adrenergic blockade and an experience multi-specialist team results in a successful management oh this high-risk clinical condition.

\section{CASE REPORT}

A 32-year-old caucasian woman, multípara, was admitted, in the emergency room, at 28 weeks of gestation for paroxysmal hypertension and tachycardia after four months. The episodes of tachycardia had started four months ago. Personal and family history were unremarkable and the current pregnancy was otherwise uncomplicated. Cell blood count and hepatic, renal and thyroid function tests were normal, with no proteinuria. The electrocardiogram (ECG) was also normal. For 
persistence of complaints, she was admitted as impatient to clarify the situation. During hospitalization, she maintained a labile blood pressure (BP) profile with maximum peaks of systolic blood pressure $220 \mathrm{mmHg}$ and diastolic blood pressure $140 \mathrm{mmHg}$ (BP ranging - systolic BP 110-220 $\mathrm{mmHg}$ and diastolic BP 62-140 $\mathrm{mmHg}$ ) accompanied with headache and diaphoresis. We started antihypertensive treatmcent on the second day of hospitalization with nifedipine and the case was discussed with the cardiology and internal medicine. Holter revealed sinusal tachycardia, not recoverable and without significant bradyarrhythmias. The transthoracic echocardiogram was also normal. The 24 hours ambulatory blood pressure monitoring (ABPM) revealed a systolic-diastolic nocturnal and systolic diurnal borderline hypertensive tension pattern; not "dipper" pattern.

The 24 hour-urine did not reveal proteinuria and soluble fms-like tyrosine kinase 1: placental growth factor (sFlt-1: PIGF) ratio was negative. In serial analysis, no changes were detected suggestive of pre-eclampsia. Despite first impression of this case was pregnancy-induced hypertension, evidence of labile blood pressure and difficult-to-control hypertension associated with tachycardia and diaphoresis lead to a suspicion of pheochromocytoma. To clarify this suspicion, we performed several imaging tests: Renal ultrasonography revealed a solid and heterogeneous mass of $44 \times 42 \times 41$ $\mathrm{mm}$, adjacent to the upper pole of the left kidney and outer to the spleen, with a hypoechogenic center and significant parenchymal vascularization, compatible with an expansive lesion of the left adrenal gland. Magnetic resonance imaging (MRI) (Figure 1) without gadolinium injection confirmed the presence of an heterogenous suprarenal mass with about $40 \mathrm{~mm}$ of indeterminate nature. Based on this findings, we proceeded to a laboratory workup for pheocromocitoma (Table 1). The 24 hours urine collection was repeated and laboratory analyses demonstrated a high concentration of urinary catecholamines: noradrenaline $1754.00 \mathrm{~g} / 24$ hours (reference value $<18.00$ ), total metanephrines urinary 8286 $\mathrm{mcg} / 24$ hours (reference value 785-300), fractioned urinary metanephrines - normetanefrine $8198 \mathrm{mcg} / 24$ hours (reference value $<444$ ), total plasma catecholamines - noradrenaline $724 \mathrm{pg} / \mathrm{ml}$ (reference value 135-300), plasmatic metanefrines - normametanephrine >>2400 $\mathrm{pg} / \mathrm{ml}$ (reference value $<196$ ) and vanilmandelic acid 23.2 $\mathrm{g} / 24$ hours (reference value $<13.6$ ).

Thus, the diagnosis of pheochromocytoma was made at 32 weeks of gestation.

After the diagnosis of the patient was transferred to a specialized center, where a multidisciplinary team consisting of obstetricians, endocrinologists, urologists, and anaesthetists was involved in the management.

The first step was to control blood pressure through adrenergic alpha blockade with phenoxybenzamine (starting in a dose of $10 \mathrm{mg} /$ day, gradually increased each
3-4 days until $30 \mathrm{mg} /$ day). The patient reported adverse effects of alpha blockade, such as nasal stufiness and orthostasis. Also, she complained of occasional palpitations accompanied with nausea and vomiting, compatible with events of reflex tachycardia (heart rate $160-180 \mathrm{bpm}$ ). Therefore, we add beta blockage to the medication (propanolol $10 \mathrm{mg} /$ day), which effectively reduced these events.

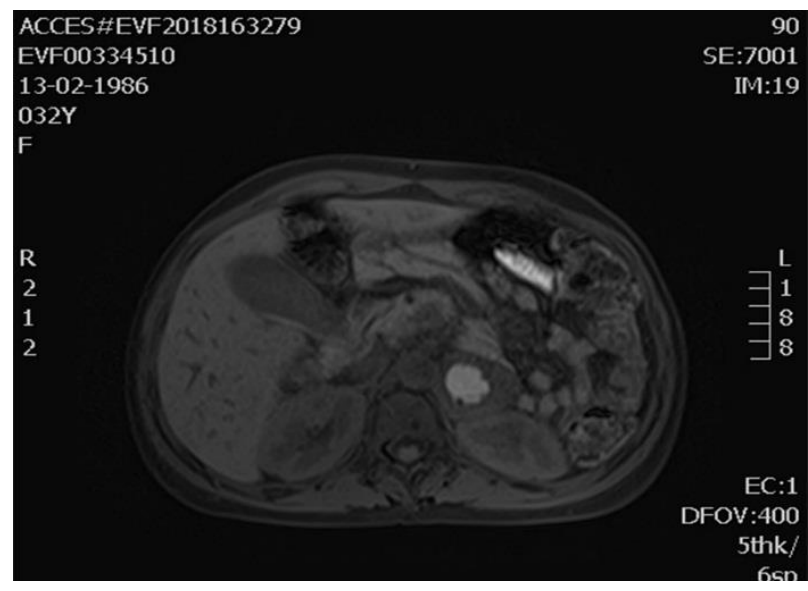

Figure 1: Abdominal resonance imaging revealing a large mass originating from the left adrenal gland.

Table 1: Laboratory investigation of pheocromocitoma.

\begin{tabular}{|c|c|}
\hline 24-hour urine & Value (reference value) \\
\hline \multicolumn{2}{|l|}{ Catecholamines } \\
\hline Adrenaline & $\begin{array}{l}71,00 \mathrm{~g} / 24 \text { hours (reference value } \\
<18,00 \text { ) }\end{array}$ \\
\hline Noradrenaline & $\begin{array}{l}1754,00 \mathrm{~g} / 24 \text { hours (reference } \\
\text { value }<76,00 \text { ) }\end{array}$ \\
\hline $\begin{array}{l}\text { Total } \\
\text { metanephrines }\end{array}$ & $\begin{array}{l}8286 \mathrm{mcg} / 24 \text { hours (reference value } \\
<785 \text { ) }\end{array}$ \\
\hline Metanephrine & $\begin{array}{l}88 \mathrm{mcg} / 24 \text { hours (reference value } \\
<341 \text { ) }\end{array}$ \\
\hline Normetanephine & $\begin{array}{l}8198 \mathrm{mcg} / 24 \text { hours (reference value } \\
<444)\end{array}$ \\
\hline $\begin{array}{l}\text { Vanilmandelic } \\
\text { acid }\end{array}$ & $\begin{array}{l}23,2 \mathrm{~g} / 24 \text { hours (reference value } \\
<13,6)\end{array}$ \\
\hline \multicolumn{2}{|c|}{ Total plasma catecholamines } \\
\hline Adrenaline & $\begin{array}{l}13 \mathrm{pg} / \mathrm{ml} \text { (reference value } 20.00 \text { - } \\
60.00 \text { ) }\end{array}$ \\
\hline Noradrenaline & $\begin{array}{l}724 \mathrm{pg} / \mathrm{ml} \text { (reference value } 135- \\
300)\end{array}$ \\
\hline \multicolumn{2}{|c|}{ Plasmatic metanephrines } \\
\hline Metanephrines & $30 \mathrm{pg} / \mathrm{ml}($ reference value $<65)$ \\
\hline $\begin{array}{l}\text { Normametanephri } \\
\text { nes }\end{array}$ & $\begin{array}{l}>2400 \mathrm{pg} / \mathrm{ml} \text { (reference value } \\
<196)\end{array}$ \\
\hline
\end{tabular}

In total, she was treated 35 days with phenoxybenzamine and 18 days with propranolol. It was essential compliance with a high sodium diet and vigorous fluid replacement. Blood pressure remained controlled and there were no hypertensive events during hospitalization (BP ranging - 
systolic BP 100-110 mmHg and diastolic BP 62-80 $\mathrm{mmHg}$ ).

In the 36 weeks of pregnancy the growth of patients' fetus was in the 10th centile, showing a decrease of fetal growth. The Doppler study of the umbilical artery flow was normal until 37 weeks of pregnancy.

Taking into account clinical stability and fetal well-being, it was decided to keep the pregnancy to term. For contraindication to vaginal delivery, a cesarean section was scheduled at 37 weeks of pregnancy.

The surgery was successful, except for an episode of bradycardia $(\mathrm{HR}=35 \mathrm{bpm})$ that occurred prior to anesthetic induction and was solved without other conditions. A baby girl was delivered, weighing $2649 \mathrm{~g}$ and the neonatology review was satisfactory. The newborn was admitted to the neonatal intensive care unit and recovered well, being discharged to home 48 hours after birth. There were no periods of hypotension, respiratory depression, or other complications. The mother was submitted to medical suppression of lactation with bromocriptine and her postpartum period was uneventful.

Four days after the cesarean section, the patient underwent a laparoscopic adrenalectomy. Anatomohistological tests confirmed the preoperative diagnosis of pheochromocytoma. The patient was discharged five days after the operation. Post-operatively, the patient's blood pressure was controlled without antihypertensive agents, with normalisation of urine catecholamine levels. Three months later the patient and her baby remain healthy.

\section{DISCUSSION}

The prevalence of pheochromocytoma in patients with hypertension is $0.2-0.6 \%$ in the general outpatient setting. Its incidence in pregnancy is not known and the prevalence is estimated at one in 54,000 pregnancies. ${ }^{3}$ In $90 \%$ of cases the presentation is typical with classical symptoms (paroxysmal hypertension, headaches, sweating, and palpitations). ${ }^{4}$

The diagnosis of pheochromocytoma during pregnancy requires a high index of suspicion and is often missed because these tumors have the ability to produce signs and symptoms that mimic other forms of hypertension, including the new-onset hypertensive syndromes in pregnancy (gestational hypertension, and preeclampsia).

Clinical diagnosis, biochemical tests, and imaging are important to establish the definitive diagnosis. ${ }^{4}$ Plasma free metanephrines or urinary fractionated metanephrines are highly sensitive and yield a significant negative predictive value. ${ }^{3}$ Surgery is the definitive treatment of pheochromocytoma, however there is controversy about the appropriate time. ${ }^{5,6}$ Some authors refer that the optimal timing for surgery is during the late first trimester or early second trimester. When diagnosed in the late second or third trimester, pheochromocytoma is best managed medically until close to term when combined caesarean section followed by tumor resection can be performed. ${ }^{5,6}$ Vaginal delivery should be avoided as it may trigger a hypertensive crisis. ${ }^{7}$ The laparoscopic approach is now the preferred technique (eg: tumor $<6 \mathrm{~cm}$ or non-invasive) as it is associated with lower postoperative morbidity and shorter hospital stay compared with conventional laparotomy. ${ }^{6,7}$

Appropriate preoperative medical management to control hypertension is essential to prevent catecholamineinduced serious complications. Alpha-adrenergic receptor blockers should be used for preoperative management of hypertension as first choice and among the alpha-blocking agents, phenoxybenzamine is the most common drug used during pregnancy. ${ }^{8}$ Multidisciplinary care involving the endocrinologist, anesthesiologist, obstetrician and urologist is essential for an optimal outcome and to minimize disease-related complications. ${ }^{3}$ In conclusion, pheochromocytoma during pregnancy is a rare entity with a high maternal and fetal mortality rate and this diagnosis can be difficult due to the low incidence of pheochromocytoma during pregnancy (0.0007\%) compared to the incidence of hypertension during pregnancy $(5-10 \%)$. Timely diagnosis and proper treatment are of utmost important to reduce maternal and fetal mortality. MRI is the preferred imaging modality for radiological localization of the tumor during pregnancy. ${ }^{3}$ In pregnancy, depending on the gestation at which diagnosis is made. When pregnancy is more advanced, medical management followed by combined caesarean section and tumor resection closer to term is preferred.

\section{CONCLUSION}

Pheochromocytoma during pregnancy is a rare entity with a high maternal and fetal mortality rate. Most successful outcomes can be achieved with the contribution of a multidisciplinary team with high level expertise, timely diagnosis and proper treatment.

\section{Funding: No funding sources Conflict of interest: None declared \\ Ethical approval: Not required}

\section{REFERENCES}

1. Giampaolino P, Della Corte L, Formisano C, Cuomo L, Maurea S, Romeo V, Bifulco G. Successful management of a third-trimester pregnancy complicated by pheochromocytoma: case report. Gynecol Endocrinol. 2018;34(12):1016-8.

2. Donatini G, Kraimps JL, Caillard C, Mirallie E, Pierre F, De Calan L, Hamy A, Larin O, Tovkay O, Cherenko S. Pheochromocytoma diagnosed during pregnancy: lessons learned from a series of ten patients. Surg Endosc. 2018;32(9):3890-900. 
3. Yulia A, Seetho IW, Ramineni A, Jaiyesimi RAK. Pheochromocytoma in Pregnancy: A Review of the Literature. Obstet Gynecol Cases Rev. 2016;3:096.

4. Santos D, Barbisan C, Marcelliini C, Santos R. Feocromocitoma e gravidez: relato de caso e revisão atualizada. J Bras Nefrol. 2015.

5. Lenders JW. Pheochromocytoma and pregnancy: a deceptive connection. Eur J Endocrinol. 2012;166(2):143-50.

6. van der Weerd K, van Noord C, Loeve M, Knapen MFCM, Visser W, de Herder WW, Franssen G, van der Marel CD, Feelders RA. Endocrinology in pregnancy: Pheochromocytoma in pregnancy: case series and review of literature. Eur $\mathbf{J}$ Endocrinol. 2017;177(2):49-58.
7. Reklou, Kamparoudis A, Mamopoulos A. Management of pheochomocytoma in pregnancy: case report and reviwe the literatute. The Open Hypertension Journal. 2013.

8. Ghalandarpoor-Attar SN, Ghalandarpoor-Attar SM, Borna S. A rare presentation of pheochromocytoma in pregnancy: a case report. J Med Case Reports. 2018;12:37.

Cite this article as: Silva R, Carvalho CR, Tavares MA, Pedroso C, Tapadinhas P. Pheochromocytoma during pregnancy - a rare diagnose with a complex multidisciplinary approach. Int J Reprod Contracept Obstet Gynecol 2021;10:3587-90. 